\title{
Impact of fundoplication for gastroesophageal reflux in the outcome of benign tracheal stenosis
}

\author{
Edno Tales Bianchi, MD, ${ }^{a}$ Paulo Francisco Guerreiro Cardoso, MD, MSc, PhD, ${ }^{b}$ \\ Helio Minamoto, MD, PhD, ${ }^{\mathrm{b}}$ Benoit Jacques Bibas, MD,${ }^{\mathrm{b}}$ Michele Salati, MD, $\mathrm{PhD},{ }^{\mathrm{c}}$ and \\ Paulo Manuel Pego-Fernandes, MD, PhD, ${ }^{b}$ The Surgery of the Digestive Tract Group ${ }^{\mathrm{d}}$
}

\section{ABSTRACT}

Objective: This study focuses on the impact of antireflux surgery in the outcome of tracheal stenosis.

Methods: We performed a retrospective study including patients with benign
tracheal stenosis who underwent esophageal manometry and dual-probe
24-hour ambulatory esophageal $\mathrm{pH}$ study. Patients with an abnormal $\mathrm{pH}$ study
were managed with laparoscopic modified Nissen fundoplication or medically
(omeprazole $80 \mathrm{mg} / \mathrm{d}$, orally). Patients with normal pH study results were
observed. After a 24-month follow-up, the outcome was considered satisfactory
if tracheal stenosis could be managed by resection and there was no need for
further dilatation or definitive decannulation. The management groups were
compared using propensity score matching.

Results: A total of 175 patients were included. Abnormal $\mathrm{pH}$ study results were found in 74 patients $(42.3 \%$ ), and $12.6 \%$ of patients had typical gastroesophageal reflux symptoms. Follow-up was completed in 124 patients ( 20 had fundoplication, 32 received omeprazole, and 72 were observed). After propensity score matching, the outcome of tracheal stenosis in the fundoplication group was similar to that of the observation group (odds ratio, $1 ; P=.99$ ) and better than that of the omeprazole group (odds ratio, 5.31; $P=.03$ ). The observation (no gastroesophageal reflux) group had a better outcome of stenosis than those treated with omeprazole (odds ratio, $3.54 ; P=.02$ ).

Conclusions: The outcome of the airway stenosis was superior after laparoscopic fundoplication compared with medical treatment with omeprazole and was similar to the outcome of patients without gastroesophageal reflux. A prospective randomized trial is warranted. (J Thorac Cardiovasc Surg 2019;158:1698-706)

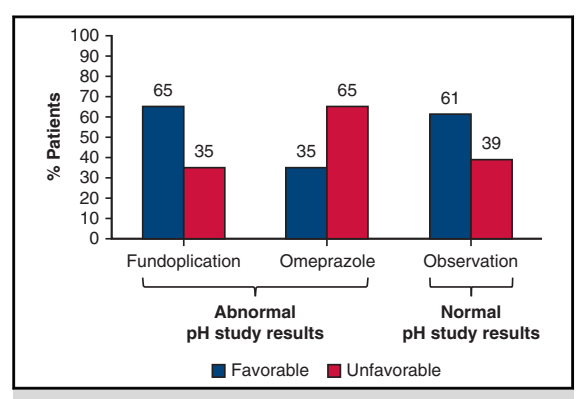

Frequency of the outcomes of tracheal stenosis according to the management strategy.

\section{Central Message}

Detection of pathologic GER and its treatment by fundoplication yield a better outcome of benign tracheal stenosis compared with medical treatment with high-dose omeprazole.

\section{Perspective}

The positive impact of antireflux surgery in the outcome of benign tracheal stenosis in patients with pathologic GER may change the future management strategy of airway stenosis.

See Commentaries on pages 1707 and 1708.
From the a Department of Gastroenterology, Discipline of Surgery of the Digestive Tract, Hospital das Clinicas HCFMUSP, Faculdade de Medicina, Universidade de Sao Paulo, Sao Paulo-SP, Brazil; ' Division of Thoracic Surgery, Instituto do Coracao, Hospital das Clinicas HCFMUSP, Faculdade de Medicina, Universidade de Sao Paulo, Sao Paulo-SP, Sao Paulo, Brazil; ' ${ }^{\mathrm{D}}$ Division of Thoracic Surgery, University of Ancona, Ancona, Italy; and ${ }^{\mathrm{d}}$ Department of Gastroenterology, Discipline of Surgery of the Digestive Tract, Esophageal Function Laboratory, Hospital das Clinicas HCFMUSP, Faculdade de Medicina, Universidade de Sao Paulo, Sao Paulo-SP, Sao Paulo, Brazil.

The Surgery of the Digestive Tract Group: Ivan Cecconello, MD, PhD, Ary Nasi, MD, $\mathrm{PhD}$, and Rubens Antonio Aissar Sallum, MD, PhD.

Received for publication Jan 2, 2019; revisions received July 24, 2019; accepted for publication July 29, 2019; available ahead of print Oct 3, 2019.

Address for reprints: Paulo Francisco Guerreiro Cardoso, MD, MSc, PhD, Divisao de Cirurgia Toracica, Instituto do Coracao, Hospital das Clinicas HCFMUSP, Rua Dr. Eneas de Carvalho Aguiar 44, bloco 2, 7 andar, Sao Paulo-SP, 05403-904 Brazil (E-mail: cardosop@gmail.com).

0022-5223/\$36.00

Copyright (c) 2019 by The American Association for Thoracic Surgery https://doi.org/10.1016/j.jtcvs.2019.07.111
Postintubation airway stenosis is a complex problem that often requires multiple interventions for treatment and poses a negative impact on the patient's quality of life. The reported incidence of tracheal stenosis after tracheostomy and laryngotracheal intubation varies from $0.6 \%$ to $21 \% .^{2}$ Gastroesophageal reflux (GER) is associated with a wide spectrum of respiratory diseases, including pulmonary fibrosis, bronchiectasis, and asthma. ${ }^{3-5}$ The association between laryngopharyngeal reflux and subglottic stenosis has been described, particularly in idiopathic tracheal stenosis, but its correlation remains controversial. ${ }^{6}$

The high number of patients referred to our center with complex airway stenosis, such as subglottic, laryngotracheal, long-segment, postresection recurrences of tracheal stenosis, and persistent inflammation at the stenosis site, led us to investigate the involvement of other potential 


\section{Abbreviations and Acronyms \\ BMI = body mass index \\ GER = gastroesophageal reflux \\ GERD $=$ gastroesophageal reflux disease \\ LES = lower esophageal sphincter \\ PSM = propensity score matching \\ UES = upper esophageal sphincter}

contributing factors such as GER. The detection of GER relies on the usual clinical manifestations such as heartburn and acid regurgitation, which are often absent or undetectable in patients with respiratory disease unless a specific diagnostic workup is carried out using esophageal motility and ambulatory 24-hour $\mathrm{pH}$ studies. On the basis of the clinical findings, outcome of tracheal stenosis, and results of the esophageal function, we hypothesized that GER can potentially influence the outcome of benign tracheal stenosis.

The present study is focused on the impact of antireflux surgery in the outcome of benign tracheal stenosis in patients with pathologic acid reflux.

\section{PATIENTS AND METHODS}

The study was approved by the hospital's ethics committee (Cappesq 1.195.397;1.684.969). The study design was retrospective and included adult patients with benign airway stenosis seen at the Division of Thoracic Surgery Trachea and Airway clinic between August 2011 and May 2017. Patients signed the generic informed consent of the hospital for diagnostic and surgical procedures. Data collection was extracted from the electronic patient records by diagnosis and was blinded for the patient's name. Data collection included the demographics and presence of typical GER symptoms, defined as the association of heartburn and acid regurgitation occurring at least once per week. Any degree of dysphagia regardless of aspiration and presence of other respiratory symptoms, such as dyspnea, cough, and stridor, were recorded. Previous treatments of the stenosis (tracheostomy, dilatation, and previous tracheal resection) were also recorded. Location and length of the airway stenosis were obtained by airway endoscopy and computed tomography scan with reconstructions. The criteria for performing the esophageal function studies included one of the following: high tracheal stenosis (proximal end within $4 \mathrm{~cm}$ below the vocal cords); blind-end stenosis (Myer-Cotton grade 4$)^{7}$; recurrent tracheal stenosis refractory to dilatation ( $\geq 3$ dilatation sessions); and recurrent stenosis within 5 years after tracheal resection. Patients with previous antireflux surgery, esophagectomy, gastrectomy, and incomplete follow-up were excluded. A 2-year follow-up was considered as complete. All patients who did not complete follow-up were excluded.

Esophageal motility and 24-hour $\mathrm{pH}$ studies were performed in the same esophageal motility laboratory by 1 investigator (A.N.). Manometry used an 8-channel, water-perfused catheter connected to a low-compliance pneumohydraulic pump (Multiplex II, Alacer Biomedica, Sao Paulo, Brazil). The lower esophageal sphincter (LES) and upper esophageal sphincter (UES) position and pressure, esophageal body motility pattern, and pressures were recorded. Normal values used were the standardized values of the laboratory. ${ }^{8}$ The 24-hour ambulatory esophageal $\mathrm{pH}$ monitoring consisted of a dual-channel antimony electrode catheter and a logger (AL-3, Alacer Biomedica). The distal tip of the probe was positioned $5 \mathrm{~cm}$ above the upper end of the LES located by manometry. The proximal electrode was located between 15 and $18 \mathrm{~cm}$ above the distal electrode. Antacid and prokinetic medications were suspended 7 days before esophageal function testing.
The $\mathrm{pH}$ study used the $\mathrm{pH}$ less than 4 cutoff for acid reflux, and the results used standard reference values. ${ }^{9}$ Abnormal (pathologic) reflux was considered when the DeMeester score was greater than 14.7. Data were retrieved from the medical records of the patients and collected by 2 investigators blinded for patient identity. Data collected were plotted on Excel (Microsoft Inc, Redmond, Wash) and transferred later to a RedCap platform (RedCap version 7. 6.10, Vanderbilt University, Nashville, Tenn).

\section{Study Groups}

- Fundoplication. Patients with pathologic reflux included in the 24-hour ambulatory esophageal $\mathrm{pH}$ study were considered for laparoscopic fundoplication in multidisciplinary rounds. Main criteria included the presence of reflux complications (eg, severe erosive esophagitis, Barrett's), typical GER symptoms, clinical treatment failure, and patient consent. Additional criteria included DeMeester score greater than 30, the absence of severe comorbidities (type 1 diabetes, severe cardiovascular condition, kidney failure, asthma, or chronic obstructive pulmonary disease), and body mass index [BMI] greater than $30 \mathrm{~kg} / \mathrm{m}^{2}$.

- Omeprazole. Patients with pathologic GER as detected by 24-hour ambulatory esophageal $\mathrm{pH}$ study who did not fulfill the criteria for fundoplication received omeprazole ( $40 \mathrm{mg}$ twice per day orally), regardless of the presence of typical upper gastrointestinal symptoms.

- Observation (no GER). Patients with a normal 24-hour esophageal pH study were followed during the study period.

Patients treated with omeprazole received gratuitous medication provided by the hospital's dispensary. Adherence to treatment was checked bimonthly during visits to the outpatient clinic. A laparoscopic modified Nissen fundoplication was performed under general anesthetic using a 4-port technique. A $360^{\circ}$ tension-free 1.5 - to 2-cm wrap of the gastric fundus was constructed around the distal esophagus after transhiatal mobilization to allow approximately $3 \mathrm{~cm}$ of intra-abdominal esophagus and division of the short gastric vessels. ${ }^{10,11}$ Repeat esophageal motility and dual-probe 24 -hour $\mathrm{pH}$ study were carried out 6 months after the fundoplication.

\section{Definition of Outcomes}

The data collected for sample characterization included age, sex, BMI, symptoms (dyspnea, dysphonia, heartburn, acid regurgitation, phlegm, dysphagia, stridor, globus), presence of lower esophageal or body sphincter hypotonia, presence of supraesophageal reflux, DeMeester score, presence of tracheostomy, recurrence of previous treatment of the stenosis, and other treatment used for the tracheal stenosis. Favorable outcome of the tracheal stenosis was considered when at completion of the 2-year follow-up the patient achieved 1 of the following conditions: stability of the stenosis not requiring further dilatation or allowing for definitive decannulation using standardized criteria $^{12}$ or tracheal resection was performed successfully according to endoscopic and radiology assessment. Unfavorable outcome was considered when none of those outcomes were achieved after 2 years of follow-up.

\section{Statistical Analysis}

Descriptive analysis for numeric data was represented as mean and standard deviation. Categoric data are represented as frequencies and percentages. For comparison of several proportions and variance among the 3 groups, we used the chi-square test and analysis of variance. For analysis among the treatment groups, the comparison was performed in pairs (fundoplication $\times$ omeprazole, fundoplication $\times$ observation, omeprazole $\times$ observation). A Fisher test was performed for categoric variables. For continuous variables, the statistical difference between the groups was calculated using Mann-Whitney and Brunner-Munzel $t$ tests. DeMeester score and BMI were confounding factors in the analysis causing selection bias. Propensity score matching (PSM) was then performed to mitigate the effects of sample inequality and used in the comparison between the patient groups. Matching between the groups was performed 
using the PSM by the "closest neighbors" algorithm. ${ }^{13}$ The variables used in the pairing were previously selected by the Levene and Kruskal-Wallis tests for the continuous variables and by the chi-square test for the categoric variables, considering the 3 groups (fundoplication, observation, and omeprazole). The variables that showed statistical significance in this first step were used within the STEP-AIC forward method in each pairing. The variables used in PSM were chosen by the Akaike criteria ${ }^{14}$ and were DeMeester score, age, and BMI, because they had significance and were present in all the pairings. Pairing quality was ascertained using distance density graphs. Group comparison was done by logistic regression using the stepwise-forward method. All PSM analyses used SPSS 21 for Windows (SPSS Inc, Chicago, Ill) and R Core team software version 3.4.1 (R Foundation for Statistical Computing, Vienna, Austria).

\section{RESULTS}

A total of 175 patients were included (106 male and 69 female; median age, 38.5 years; range, $13-85$ years). A total of 162 patients $(92.5 \%)$ had a history of orotracheal intubation with a median duration of 17.1 days. Other causes in the remaining patients were idiopathic (9), postinfectious stenosis (3), and Wegener's granulomatosis (1). The location of the stenosis was subglottic in $94(53.7 \%)$, tracheal in $61(34.8 \%)$, and laryngotracheal in $20(11.4 \%)$. The median extension of the stenosis was $2.6 \mathrm{~cm}$. Tracheal restenosis accounted for $42(27.4 \%)$ of all patients. There were 145 patients $(82.8 \%)$ with a tracheostomy; $75(42.8 \%)$ of those had a previous resection (42 tracheal resections, 23 laryngofissures, 10 subglottic resections). Dilatation was performed in 48 patients $(27.4 \%)$ (1.1 dilatations/patient). Stenting was required to maintain airway patency in $160 \mathrm{pa}-$ tients $(69.7 \%)$. A silicone T-tube was used in 122 patients $(69.7 \%)$, and 88 were placed with the vertical limb below the vocal cords. A Dumon stent was used in 38 patients $(21.7 \%)$. BMI of the cohort was $26.9 \pm 4.7 \mathrm{~kg} / \mathrm{m}^{2}$, and there was no significant difference between normal and an abnormal pH study $\left(27 \pm 5.1 \mathrm{~kg} / \mathrm{m}^{2}, 26.6 \pm 4 \mathrm{~kg} / \mathrm{m}^{2}\right.$, respectively; $P=.91$ ) or between normal and abnormal esophageal manometry findings $(P=.59)$.

An abnormal esophageal motility was found in 63 of 171 manometries (37.3\%), and hypotonic LES was the predominant finding $(67.1 \%)$. Esophageal body motor abnormality was found in 28 patients (44.4\%), 20 patients showed hypomotility, and 5 patients had hypercontractility of the distal esophagus. Other findings included nonspecific motility disorder (1), diffuse esophageal spasm (1), and hypertonic UES (1). The presence of an abnormal esophageal motility in this cohort was not affected by age or gender $(P=.504$ and $P=.435$, respectively). The presence of dysphagia was not different between normal and abnormal esophageal manometry $(13.2 \%$ and $14.3 \%$, respectively; $P=.843)$.

There were 175 dual-probe 24-hour ambulatory $\mathrm{pH}$ studies. There were 74 patients $(42.3 \%)$ with an abnormal $\mathrm{pH}$ study, and all had postintubation tracheal stenosis. These patients had a higher number of distal acid reflux episodes, higher orthostatic and supine acid reflux exposure, and twice as much supraesophageal reflux. Upper gastrointestinal endoscopy was performed in 54 patients $(30.6 \%)$ (20 patients with normal pH study and 34 patients with abnormal $\mathrm{pH}$ study). Abnormalities were found in 10 patients $(18.5 \%): 8$ patients with an abnormal $\mathrm{pH}$ study and 2 patients with a normal $\mathrm{pH}$ study. Esophagitis was found in 8 patients, Barrett's esophagus was found in 1 patient, and hiatus hernia was found in 1 patient.

Dominant symptoms were dyspnea $(89.7 \%)$, dysphonia $(34.3 \%)$, heartburn $(31.6 \%)$, and acid regurgitation $(27.6 \%)$. Patients with an abnormal $\mathrm{pH}$ study had a higher incidence of heartburn $(67.3 \%)$ and acid regurgitation $(56.3 \%)$ compared with those with a normal $\mathrm{pH}$ study $(32.7 \%, P=.0001 ; 34.8 \%, P=.024$, respectively). A combination of heartburn-acid regurgitation occurred in $21.1 \%$ of the patients and was related to a higher chance of an abnormal $\mathrm{pH}$ study (odds ratio, 2.42; 95\% confidence interval, 0.156-5.090; $P=.017$ ). Dyspnea, dysphonia, phlegm, stridor, and globus were not different between patients with normal and abnormal $\mathrm{pH}$ study results.

Among the 175 patients, 51 were excluded because they had not completed the 2-year follow-up, leaving 124 for analysis (52 with an abnormal $\mathrm{pH}$ study and 72 with a normal $\mathrm{pH}$ study) (Figure 1). The percentage of patients with a previous tracheal resection was similar in both the fundoplication and omeprazole groups, and smaller in the observation (no GER) group $(20 \%, 17.6 \%$, and $9.7 \%$, respectively). The treatment for tracheal stenosis was categorized into tracheal resection, dilatation, and stenting with a Dumon stent or a silicone T-tube (Table 1).

The percentage of patients with a favorable outcome of stenosis in the fundoplication group $(65 \%)$ was similar to that in the observation group $(61 \%)$ and higher than in

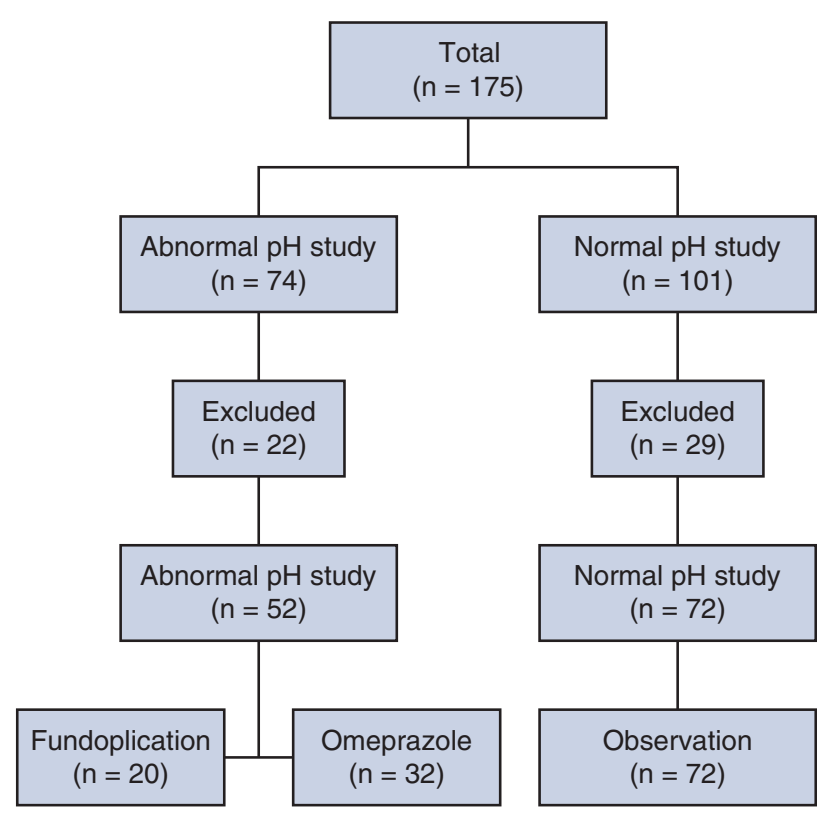

FIGURE 1. Flowchart showing the distribution of the patients in the study. 
TABLE 1. Patient demographics showing frequencies distributed by groups

\begin{tabular}{|c|c|c|c|c|}
\hline Patient demographics $(n=124)$ & Fundoplication $(\mathbf{n}=20)$ & Omeprazole $(\mathbf{n}=32)$ & Observation $($ no GER) $(n=72)$ & $\boldsymbol{P}^{*}$ \\
\hline Age & $33.5 \pm 12.2$ & $47.7 \pm 15.4$ & $43.9 \pm 18.6$ & .012 \\
\hline BMI & $23.7 \pm 2.7$ & $27.1 \pm 3.9$ & $25.9 \pm 4.9$ & .028 \\
\hline DeMeester score & $47.7 \pm 17.7$ & $30.5 \pm 22.9$ & $6.6 \pm 4.3$ & .001 \\
\hline Male $(\%)$ & $11(55)$ & $23(71.8)$ & $45(62.5)$ & .643 \\
\hline Female $(\%)$ & $9(45)$ & $9(28.1)$ & $27(37.5)$ & .354 \\
\hline Heartburn $(\%)$ & $13(65)$ & $14(43.7)$ & $15(20.8)$ & .001 \\
\hline Acid regurgitation $(\%)$ & $11(55)$ & $11(34.3)$ & $14(19.4)$ & .006 \\
\hline Hypotonic LES (\%) & $10(50)$ & $6(18.7)$ & $18(25)$ & .032 \\
\hline Tracheostomy $(\%)$ & $16(80)$ & $30(93.7)$ & $56(77.7)$ & .487 \\
\hline Previous tracheal resection $(\%)$ & $6(30)$ & $6(18.7)$ & $7(9.7)$ & .073 \\
\hline Tracheal resection $(\%)$ & $4(20)$ & $6(18.7)$ & $21(29.1)$ & .407 \\
\hline Tracheal stenosis dilatation $(\%)$ & $5(25)$ & $4(12.5)$ & $10(13.8)$ & .398 \\
\hline Silicone T-tube stent $(\%)$ & $10(50)$ & $21(65.6)$ & $32(44.4)$ & .271 \\
\hline Dumon silicone stent $(\%)$ & $1(5)$ & $3(9.3)$ & $9(12.5)$ & .779 \\
\hline Favorable outcome $(\%)$ & $13(65)$ & $12(37.5)$ & $44(61.1)$ & .028 \\
\hline
\end{tabular}

GER, Gastroesophageal reflux; BMI, body mass index; LES, lower esophageal sphincter. *Analysis of variance; chi-square. Patients undergoing fundoplication were younger and had slightly lower BMI, higher pH study scores (DeMeester), more typical reflux symptoms (heartburn and regurgitation), and a higher incidence of hypotonic LES. A higher percentage of these patients achieved a favorable outcome of the tracheal stenosis at the end of follow-up.

the omeprazole group $(37 \%)$ (Table 1). Frequency of a favorable outcome of the tracheal stenosis was higher in the fundoplication group compared with omeprazole $(P=.043)$ and in the observation (no GER) group compared with omeprazole $(P=.034)$. The PSM was performed, and the 3 groups were compared in pairs (Tables 2 and 3). After logistic regression analyses, the results were as follows:

- Fundoplication versus omeprazole: A total of 18 subjects were paired in each group. Patients who received fundoplication had a better chance of a favorable outcome than patients treated with omeprazole $(P=.03)$. The pairing quality using the distance-density graphs before and after PSM and the results of the analysis are shown in Figure 2. The covariable hypotonic LES was maintained in the model for the purpose of quality adjustment.

- Omeprazole versus observation: A total of 29 subjects were paired in each group. Patients in the observation (no GER) group had a better chance of achieving a favorable outcome compared with the patients treated with omeprazole $(P=.02)$. The covariable BMI was maintained in the model for the purpose of quality adjustment (Figure 3).

- Fundoplication versus observation (no GER): A total of 18 subjects were paired in each group. No significant difference in favorable outcome was found between the fundoplication and observation (no GER) groups $(P=.99)$. The covariable hypotonic LES was kept in the model for the purpose of quality adjustment (Figure 4). Two patients were kept on omeprazole after fundoplication.

\section{DISCUSSION}

This retrospective study using PSM showed that patients with benign tracheal stenosis in a setting of an abnormal esophageal acid exposure experienced a better outcome of the stenosis after antireflux laparoscopic fundoplication.

Airway-related problems in patients with GER carry an inflammatory component that is often associated with the presence of neutrophilic, neuroendocrine, inflammatory cells, and cytokines, thus causing airway inflammation and increased local oxidative stress. ${ }^{15}$ The potential role of GER in our patient population with benign tracheal stenosis was considered after the observation of persistent inflammation found at the stenosis site in young patients with postintubation tracheal stenosis submitted to stenting and in the late recurrences after tracheal resection. ${ }^{16}$

The acronym GER was used in this study instead of gastroesophageal reflux disease (GERD) because most subjects in the cohort did not fulfill the criteria for GERD, that is, the presence of typical symptoms regardless of an injured esophageal mucosa.

This cohort has a predominance of postintubation tracheal stenosis, high airway stenosis (subglottic or laryngotracheal), restenosis, and previous resection failures. The high number of silicone T-tube stents derives from most patients already having a tracheostomy in place upon referral to our center. Nevertheless, stenting by means of a T-tube was used mostly as a bridge to definitive treatment.

For the purpose of the study, the typical symptoms were defined as the combination of heartburn and acid 
TABLE 2. Patient demographics showing frequencies and outcomes distributed by groups after propensity score matching was applied: Group comparisons in pairs

\begin{tabular}{|c|c|c|c|c|c|c|c|c|c|}
\hline \multirow[b]{2}{*}{ Variables } & \multicolumn{3}{|c|}{ Fundoplication vs omeprazole } & \multicolumn{3}{|c|}{$\begin{array}{c}\text { Fundoplication vs } \\
\text { observation (no GER) }\end{array}$} & \multicolumn{3}{|c|}{$\begin{array}{c}\text { Observation (no GER) vs } \\
\text { omeprazole }\end{array}$} \\
\hline & $\begin{array}{l}\text { Fundoplication } \\
\qquad(N=18)\end{array}$ & $\begin{array}{c}\text { Omeprazole } \\
(\mathrm{N}=18)\end{array}$ & $\boldsymbol{P}^{*}$ & $\begin{array}{l}\text { Fundoplication } \\
\qquad(\mathbf{N}=18)\end{array}$ & $\begin{array}{c}\text { Observation } \\
(\mathbf{N}=18)\end{array}$ & $P^{*}$ & $\begin{array}{c}\text { Observation } \\
(\mathbf{N}=29)\end{array}$ & $\begin{array}{c}\text { Omeprazole } \\
(\mathbf{N}=29)\end{array}$ & $P^{*}$ \\
\hline Age & $33.6 \pm 12.9$ & $45.2 \pm 13.4$ & .012 & $33.6 \pm 12.9$ & $43.3 \pm 21.1$ & .223 & $41.5 \pm 17.0$ & $45.2 \pm 15.4$ & .316 \\
\hline BMI & $23.7 \pm 2.9$ & $27 \pm 3.8$ & .007 & $23.7 \pm 2.9$ & $24.3 \pm 5.2$ & .798 & $25.9 \pm 5.1$ & $27.3 \pm 4$ & .129 \\
\hline DeMeester score & $\begin{array}{c}\text { Before } 47.7 \pm 17.7 \\
\text { After } 6.8 \pm 13\end{array}$ & $26.8 \pm 12$ & $<.001$ & $\begin{array}{c}\text { Before } 47.7 \pm 17.7 \\
\text { After } 6.8 \pm 13\end{array}$ & $9.3 \pm 4.3$ & $<.001$ & $2.6 \pm 1.6$ & $31.48 \pm 24.4$ & $<.001$ \\
\hline \multicolumn{10}{|l|}{ Gender $(\%)$} \\
\hline Male & $5(27.7)$ & $3(16.6)$ & .691 & $5(27.7)$ & $5(27.7)$ & 1 & $11(37.9)$ & $8(27.5)$ & .576 \\
\hline Female & $13(72.2)$ & $15(83.3)$ & & $13(72.2)$ & $13(72.2)$ & & $18(62.0)$ & $21(72.4)$ & \\
\hline Heartburn $(\%)$ & $12(66.6)$ & $9(50)$ & .5 & $12(66.6)$ & $0(0)$ & $<.001$ & $5(17.2)$ & $13(44.8)$ & .045 \\
\hline Acid regurgitation (\%) & $10(55.5)$ & $7(38.8)$ & .505 & $10(55.5)$ & $2(11.1)$ & .012 & $4(13.7)$ & $11(37.9)$ & .07 \\
\hline Hypotonic LES (\%) & $9(50)$ & $2(11.1)$ & .027 & $9(50)$ & $7(38.8)$ & .738 & $3(10.3)$ & $6(20.6)$ & .47 \\
\hline Tracheostomy (\%) & $15(83.3)$ & $17(94.4)$ & .603 & $15(83.3)$ & $13(72.2)$ & .691 & $24(82.7)$ & $25(86.2)$ & 1 \\
\hline $\begin{array}{l}\text { Previous tracheal } \\
\text { resection }(\%)\end{array}$ & $5(27.7)$ & $2(11.1)$ & .402 & $5(27.7)$ & $2(11.1)$ & .402 & $2(6.9)$ & $5(17.2)$ & .423 \\
\hline Recurrence $(\%)$ & $5(27.7)$ & $3(16.6)$ & .691 & $5(27.7)$ & $5(27.7)$ & 1 & $7(24.1)$ & $6(20.6)$ & 1 \\
\hline \multicolumn{10}{|l|}{ Treatment (\%) } \\
\hline Tracheal resection & $4(22.2)$ & $4(22.2)$ & .31 & $4(22.2)$ & $4(22.2)$ & 1 & $5(17.2)$ & $6(20.6)$ & .655 \\
\hline Tracheal dilatation & $4(22.2)$ & $1(5.6)$ & & $4(22.2)$ & $1(5.5)$ & & $5(17.2)$ & $3(10.3)$ & \\
\hline T-tube silicone stent & $9(50)$ & $13(72.2)$ & & $9(50)$ & $10(55.5)$ & & $15(51.7)$ & $18(62)$ & \\
\hline Dumon silicone stent & $1(5.5)$ & $0(0)$ & & $1(5.5)$ & $0(0)$ & & $4(13.7)$ & $2(6.9)$ & \\
\hline Favorable outcome $(\%)$ & $12(66.6)$ & $5(27.7)$ & .043 & $12(66.6)$ & $10(55.5)$ & .733 & $18(62)$ & $9(31)$ & .034 \\
\hline
\end{tabular}

GER, Gastroesophageal reflux; $B M I$, body mass index; LES, lower esophageal sphincter. *Fisher, Mann-Whitney. The comparison among the 3 groups in pairs (Fisher, MannWhitney) showed that more patients undergoing fundoplication were able to achieve a favorable outcome of the tracheal stenosis compared with those treated medically (omeprazole) and had a similar frequency compared with patients in the observation (no GER) group. Conversely, only half the patients treated with omeprazole achieved a favorable outcome compared with those in the observation (no GER) group.

regurgitation found in $21 \%$ of the cohort and in only $12 \%$ patients with tracheal stenosis and an abnormal $\mathrm{pH}$ study. Such findings approximate the prevalence values for heartburn in healthy subjects previously reported in Brazil $(11.9 \%)^{17}$ and heartburn or acid regurgitation in subjects in the United States $(19.8 \%){ }^{18}$

TABLE 3. Standardized differences of the variables studied before and after propensity score matching was applied to the groups

\begin{tabular}{|c|c|c|c|c|c|c|}
\hline \multirow[b]{2}{*}{ Variables } & \multicolumn{3}{|c|}{ Before PSM } & \multicolumn{3}{|c|}{ After PSM } \\
\hline & $\begin{array}{l}\text { Fundoplication } \\
\text { vs omeprazole }\end{array}$ & $\begin{array}{c}\text { Fundoplication vs } \\
\text { observation } \\
\text { (no GER) }\end{array}$ & $\begin{array}{c}\text { Observation } \\
\text { (no GER) } \\
\text { vs omeprazole }\end{array}$ & $\begin{array}{c}\text { Fundoplication } \\
\text { vs omeprazole }\end{array}$ & $\begin{array}{c}\text { Fundoplication vs } \\
\text { observation } \\
\text { (no GER) }\end{array}$ & $\begin{array}{l}\text { Observation } \\
\text { (no GER) vs } \\
\text { Omeprazole }\end{array}$ \\
\hline Age & 0.834 & 0.674 & 0.062 & 0.703 & 0.216 & 0.245 \\
\hline DeMeester score & 0.832 & 3.406 & 1.43 & 0.554 & 3.229 & 1.668 \\
\hline BMI & 0.992 & 0.57 & 0.248 & 0.486 & 0.269 & 0.287 \\
\hline Gender & 0.004 & 0.26 & 0.265 & 0.237 & 0.352 & 0.222 \\
\hline Heartburn & 0.451 & 1.067 & 0.55 & 0.343 & 1.649 & 0.625 \\
\hline Acid regurgitation & 0.359 & 0.832 & 0.443 & 0.339 & 1.292 & 0.573 \\
\hline Hypotonic LES & 0.644 & 0.47 & 0.164 & 0.756 & 0.343 & 0.289 \\
\hline Tracheostomy & 0.08 & 0.124 & 0.204 & 0 & 0.161 & 0.095 \\
\hline Previous tracheal resection & 0.254 & 0.492 & 0.238 & 0.27 & 0.625 & 0.322 \\
\hline Stenosis recurrence & 0.166 & 0.002 & 0.164 & 0.129 & 0 & 0.083 \\
\hline Favorable outcome & 0.763 & 0.139 & 0.608 & 0.579 & 0 & 0.655 \\
\hline
\end{tabular}

PSM, Propensity score matching; GER, gastroesophageal reflux; BMI, body mass index; LES, lower esophageal sphincter. 

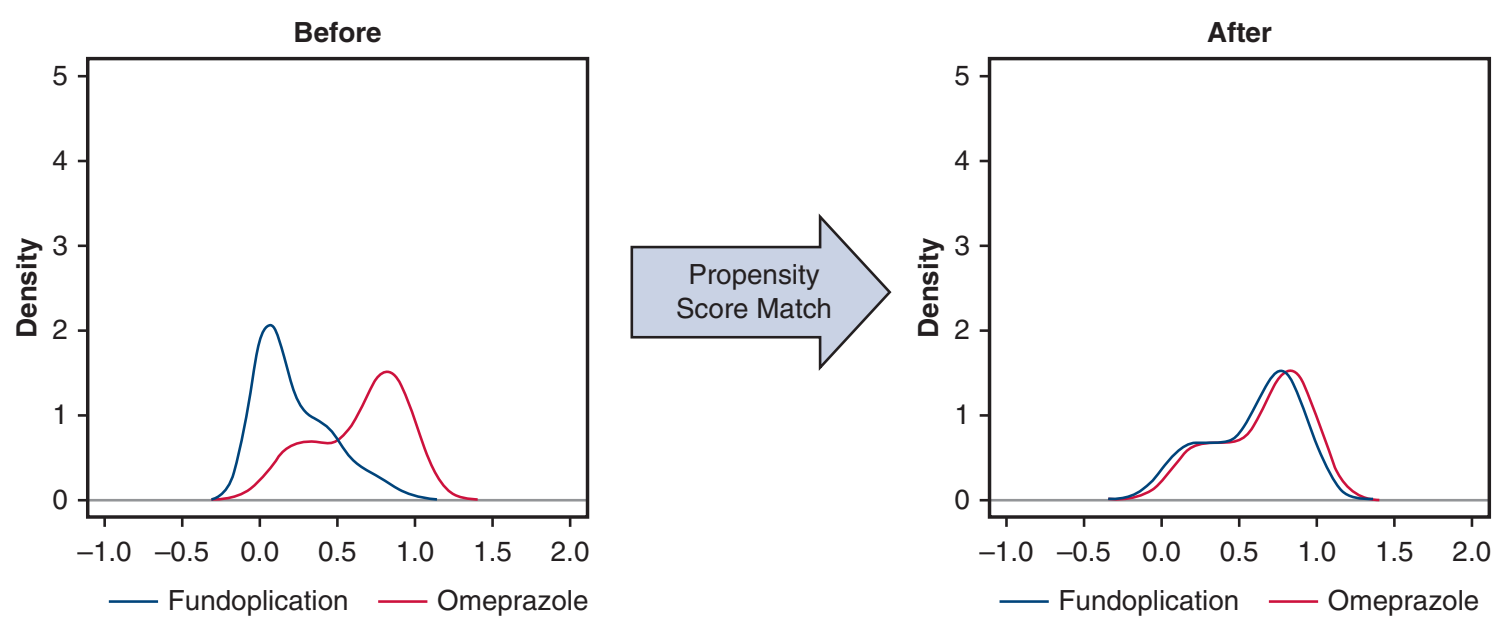

\begin{tabular}{|c|c|c|c|c|}
\hline & Odds Ratio & Standard Error & 95\% Confidence Interval & $\boldsymbol{P}$ \\
\hline Intercept & - & 0.52 & - & .31 \\
\hline Fundoplication & 5.31 & 0.79 & $2.41-11.7$ & .03 \\
\hline Hypotonic LES & 0.44 & 0.82 & $0.19-0.99$ & .31 \\
\hline
\end{tabular}

FIGURE 2. Comparison of outcomes between patients receiving fundoplication and patients receiving omeprazole. The pairing quality is shown by the distance-density graphs before and after PSM. Results of the regression analysis demonstrated that fundoplication resulted in a higher chance of resolution of the tracheal stenosis. The covariable hypotonic LES was used for quality adjustment. LES, Lower esophageal sphincter.

We elected to use a 24-hour ambulatory dual-probe esophageal $\mathrm{pH}$ study for the detection of GER regardless of the presence of typical digestive symptoms and was based on the characteristics and complexity of the stenosis. This strategy is used in other respiratory conditions, such as in lung transplant candidates in whom GER is associated with graft dysfunction, justifying a practice of universal esophageal manometry and $\mathrm{pH}$ testing in this population. ${ }^{19}$ The authors acknowledge that this approach may have limited data acquisition to ascending acid GER and overlooks the descending laryngopharyngeal reflux. In the present study, $37 \%$ of the patients undergoing esophageal manometry had esophageal motility abnormalities represented mostly by hypotonic LES followed by distal esophageal hypocontractility. The incidence of dysphagia was less than $15 \%$, and it was not different between patients with normal and abnormal esophageal manometry findings.

Unlike other airway or lung diseases, such as asthma, ${ }^{4,5}$ pulmonary fibrosis, ${ }^{3}$ bronchiolitis obliterans, ${ }^{19,20}$ and airway hyperresponsiveness, the few studies ${ }^{21-23}$ on the correlation between airway stenosis and GER are focused on idiopathic subglottic airway stenosis where the presence of gastric juice yields to tissue remodeling through the stimulation of the differentiation of fibroblasts into myofibroblasts. ${ }^{24}$

As far as postintubation tracheal stenosis is concerned, the treatment of reflux and its impact on the outcome of the stenosis have been scarcely reported. Bain and colleagues ${ }^{25}$ described the first case of successful improvement of a laryngotracheal stenosis after surgical treatment for
GERD. Experimentally, both tracheal injury and stenosis are aggravated after exposure to the acid contents of the stomach. ${ }^{26} \mathrm{Up}$ to $78 \%$ of the patients with upper airway stenosis show an abnormal 24-hour $\mathrm{pH}$ study, ${ }^{27}$ and this high prevalence of abnormal acid reflux occurs in the absence of typical digestive symptoms. A higher incidence of pharyngeal acid reflux events has been reported, and the treatment of GER improved the results of the treatment of the airway stenosis. ${ }^{28}$ Our study showed a high incidence of abnormal $\mathrm{pH}$ studies $(42 \%)$ with a predominance of supine and supraesophageal reflux, similar to previous reports in other respiratory diseases. ${ }^{3,4,20}$ Laryngotracheal stenosis is associated with an abnormal $\mathrm{pH}$ study in more than half the patients, ${ }^{22}$ whereas the laryngeal acid exposure occurs in $86 \%{ }^{6}$ Another study on tracheal stenosis found GERD in $47 \%$ of the patients, although, as opposed to our cohort, only $18 \%$ of the patients had postintubation stenosis. ${ }^{29}$

Clinical data on the effects of laryngotracheal stenosis on upper airway aerodynamics showed an increased resistance and a decreased airflow that are not compensated by mouth breathing. ${ }^{30}$ Therefore, thoracoabdominal pressure gradients may contribute to the pathogenesis of GER by overcoming the antireflux barrier function. A dog model of airway obstruction submitted to esophageal motility and a $\mathrm{pH}$ study demonstrated that the severity of reflux correlated with negative inspiratory pressure changes. ${ }^{31}$ The role of thoracoabdominal pressure gradient assessed in lung transplant candidates found GERD in $30 \%$ of the patients with a thoracoabdominal pressure gradient less than $0 \mathrm{~mm} \mathrm{Hg}$. 

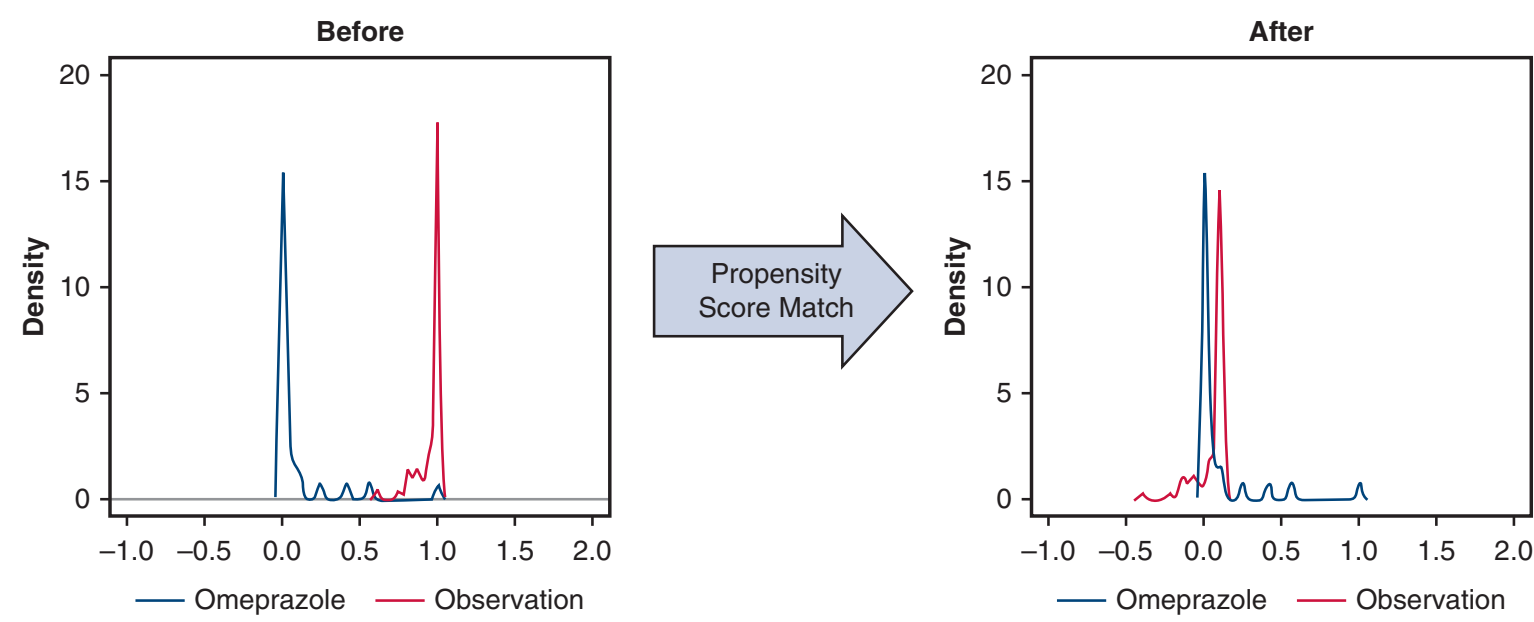

\begin{tabular}{|c|c|c|c|c|}
\hline & Odds Ratio & Standard Error & 95\% Confidence Interval & $\boldsymbol{P}$ \\
\hline Intercept & - & 1.69 & - & .91 \\
\hline Observation & 3.54 & 0.56 & $2.02-6.19$ & .02 \\
\hline BMI & 0.98 & 0.06 & $0.92-1.04$ & .71 \\
\hline
\end{tabular}

FIGURE 3. Comparison of outcomes between patients receiving medical treatment of reflux with omeprazole and patients without pathologic reflux. The pairing quality is shown by the distance-density graphs before and after PSM. Results of the regression analysis demonstrated that patients receiving treatment of reflux with omeprazole had a lower chance of resolution of the tracheal stenosis. The covariable BMI was used for quality adjustment. BMI, Body mass index.

Higher adjusted thoracoabdominal pressure gradient increased the likelihood of pathological reflux in these patients, even in the absence of a hiatus hernia or hypotonic LES. $^{32}$
Despite the pathophysiologic differences between pulmonary and central airway disease, variations in thoracoabdominal and transpulmonary pressures can be transposed to the airway dynamics when flows are altered in tracheal
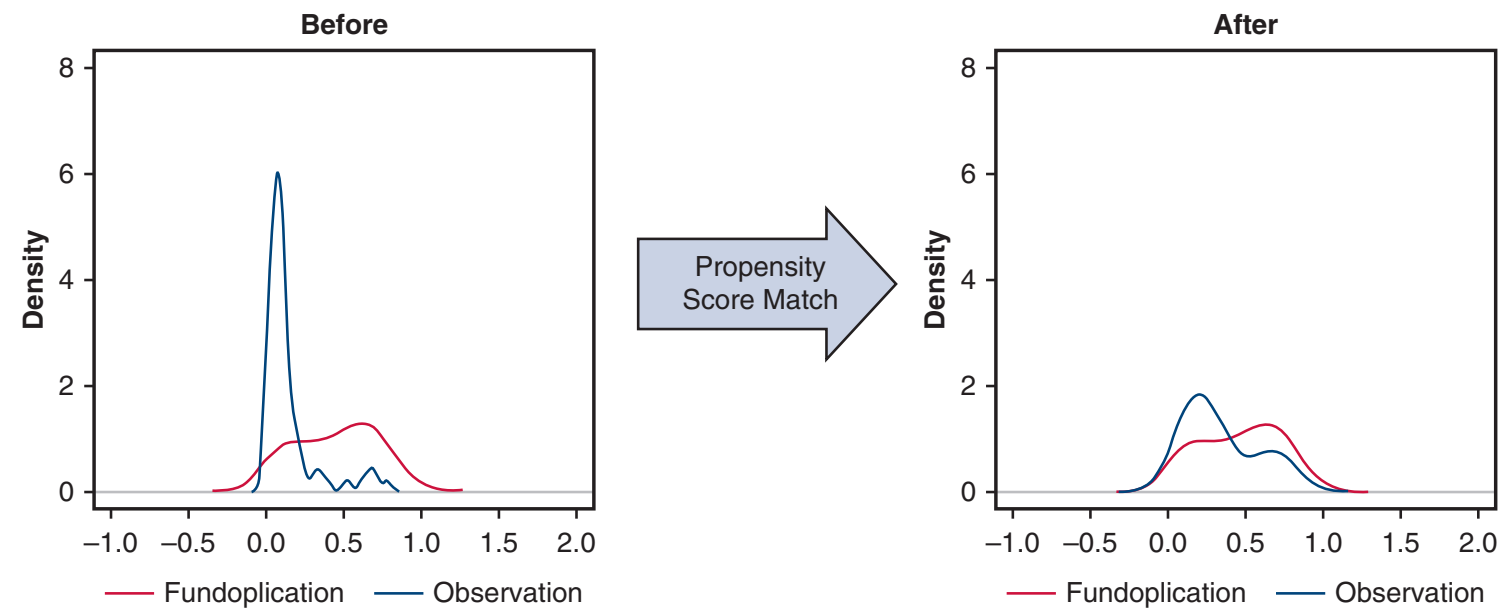

\begin{tabular}{|c|c|c|c|c|}
\hline & Odds Ratio & Standard Error & 95\% Confidence Interval & $\boldsymbol{P}$ \\
\hline Intercept & - & 0.5 & - & .5 \\
\hline Fundoplication & 1 & 0.75 & $0.47-2.11$ & .99 \\
\hline Hypotonic L.E.S. & 2.14 & 0.83 & $0.93-4.93$ & .36 \\
\hline
\end{tabular}

FIGURE 4. Comparison of outcomes between patients receiving fundoplication for the treatment of reflux and patients without pathologic reflux who were observed only. The pairing quality is shown by the distance-density graphs before and after PSM. Results of the regression analysis demonstrated that patients receiving fundoplication had a similar chance of resolution of the tracheal stenosis compared with the observation (no GER) group. The covariable hypotonic LES was used for quality adjustment. LES, Lower esophageal sphincter. 
stenosis. However, the high number of tracheostomies in our patient cohort makes this mechanism less likely to occur if one considers that the presence of an adult-size tracheostomy cannula can bypass the stenosis and reduce the local resistance to airflow during spontaneous breathing.

Another plausible explanation for the effects of acid reflux in the outcome of tracheal stenosis is the change in the local microbiome. This may be particularly important in patients using silicone stents because the stent's biofilm can change its microbiome depending on local conditions (ie, local $\mathrm{pH}$, humidity, and temperature). The exposure of the stent to aerodigestive secretions creates a microbial challenge that can harm the tracheal wall at the stenosis site. ${ }^{33}$ This enhanced and persistent local tissue aggression can potentially increase the extent and severity of the stenosis, thus delaying or impairing the definitive treatment. ${ }^{34}$

Since the first report of antireflux surgery in the treatment of tracheal stenosis, ${ }^{25}$ there were no further attempts to perform this intervention for this intent. Our study demonstrated that patients with pathologic acid reflux who underwent fundoplication had a similar outcome of the stenosis compared with subjects without pathologic reflux. Fundoplication was also associated with a better chance of an improved outcome of the tracheal stenosis compared with continuous treatment with high-dose omeprazole. Patients treated with omeprazole had a worse chance of a favorable outcome of the tracheal stenosis than patients without pathologic acid reflux or fundoplication. Omeprazole is effective in reducing the acid contents of the refluxate; however, it does not prevent supraesophageal reflux and microaspiration of gastric juice enzymes such as pepsin and other harmful components of the refluxate that can affect the tracheal stenosis. An analogous situation is described in idiopathic pulmonary fibrosis, where GER control by fundoplication reduces exacerbation of the disease and slows the decline in pulmonary function. ${ }^{35}$

We acknowledge that this study is not sufficient to define whether all patients with a tracheal stenosis and abnormal GER should undergo fundoplication. However, the results paved the ground for new studies in this intriguing area of investigation.

\section{Study Limitations}

The present study has several limitations. Its retrospective design does not allow discernment of whether or when GER was present before the onset of tracheal disease in these patients. The nonrandomized patient selection yielded to the allocation of patients with more severe reflux to the fundoplication group. The worse outcome of tracheal stenosis in the omeprazole group reinforces the idea that GER itself is harmful to the stenosis. This issue needs to be addressed in the future using $\mathrm{pH}$ monitoring with higher sensitivity such as the catheter-free system or the
impedance-pH monitoring to measure weakly acidic and nonacid reflux, which were unavailable for use in the present study because it was not available in our institution until recently.

\section{CONCLUSIONS}

In this cohort of patients with benign tracheal stenosis and GER, the outcome of the airway stenosis was superior after laparoscopic fundoplication when compared with medical treatment with omeprazole and was similar to the outcome of patients without GER. A prospective randomized trial is warranted.

\section{Conflict of Interest Statement}

Authors have nothing to disclose with regard to commercial support.

\section{References}

1. Bibas BJ, Cardoso PFG, Salati M, Minamoto H, Tamagno MFL, Terra RM, et al. Health-related quality of life evaluation in patients with non-surgical benign tracheal stenosis. J Thorac Dis. 2018;10:4782-8.

2. Grillo HC, Donahue DM, Mathisen DJ, Wain JC, Wright CD. Postintubation tracheal stenosis. Treatment and results. J Thorac Cardiovasc Surg. 1995;109: 486-93.

3. Bandeira CD, Rubin AS, Cardoso PF, Moreira Jda S, Machado Mda M. Prevalence of gastroesophageal reflux disease in patients with idiopathic pulmonary fibrosis. J Bras Pneumol. 2009;35:1182-9.

4. Machado Mda M, Cardoso PF, Ribeiro IO, Zamin Junior I, Eilers RJ. Esophageal manometry and 24-h esophageal pH-metry in a large sample of patients with respiratory symptoms. J Bras Pneumol. 2008;34:1040-8.

5. Dos Santos LH, Ribeiro IO, Sanchez PG, Hetzel JL, Felicetti JC, Cardoso PF. Evaluation of pantoprazol treatment response of patients with asthma and gastroesophageal reflux: a randomized prospective double-blind placebo-controlled study. J Bras Pneumol. 2007;33:119-27.

6. Maronian NC, Azadeh H, Waugh P, Hillel A. Association of laryngopharyngeal reflux disease and subglottic stenosis. Ann Otol Rhinol Laryngol. 2001;110: 606-12.

7. Myer CM III, O'Connor DM, Cotton RT. Proposed grading system for subglottic stenosis based on endotracheal tube sizes. Ann Otol Rhinol Laryngol. 1994;103: 319-23.

8. Richter JE, Wu WC, Johns DN, Blackwell JN, Nelson JL 3rd, Castell JA, et al. Esophageal manometry in 95 healthy adult volunteers. Variability of pressures with age and frequency of "abnormal" contractions. Dig Dis Sci. 1987;32: 583-92.

9. Jamieson JR, Stein HJ, DeMeester TR, Bonavina L, Schwizer W, Hinder RA, et al. Ambulatory 24-h esophageal $\mathrm{pH}$ monitoring: normal values, optima thresholds, specificity, sensitivity, and reproducibility. Am J Gastroenterol. 1992;87:1102-11.

10. Attwood SE, Lundell L, Ell C, Galmich JP, Hatlebakk J, Fiocca R, et al. Standardization of surgical technique in antireflux surgery: the LOTUS trial experience. World J Surg. 2008;32:995-8.

11. Stefanidis D, Hope WW, Kohn GP, Reardon PR, Richardson WS, Fanelli RD, et al. Guidelines for surgical treatment of gastroesophageal reflux disease. Surg Endosc. 2010;24:2647-69.

12. Terra RM, Bibas BJ, Minamoto H, Waisberg DR, Tamagno MFL, Tedde ML, et al. Decannulation in tracheal stenosis deemed inoperable is possible after long-term airway stenting. Ann Thorac Surg. 2013;95:440-4.

13. Smith HL. Matching with multiple controls to estimate treatment effects in observational studies. Sociol Methodol. 1997;27:325-53.

14. Akaike H. New look at statistical-model identification. Ieee T Automat Contr. 1974;Ac19:716-23.

15. Carpagnano GE, Resta O, Ventura MT, Amoruso AC, Di Gioia G, Giliberti T, et al. Airway inflammation in subjects with gastro-oesophageal reflux and gastro-oesophageal reflux-related asthma. J Intern Med. 2006;259:323-31. 
16. Cardoso PFG, Bibas BJ, Minamoto H, Pego-Fernandes PM. Prophylaxis and treatment of complications after tracheal resection. Thorac Surg Clin. 2018;28: 227-41.

17. Moraes-Filho JP, Chinzon D, Eisig JN, Hashimoto CL, Zaterka S. Prevalence of heartburn and gastroesophageal reflux disease in the urban Brazilian population. Arq Gastroenterol. 2005;42:122-7.

18. Locke GR III, Talley NJ, Fett SL, Zinsmeister AR, Melton LJ III. Prevalence and clinical spectrum of gastroesophageal reflux: a population-based study in Olmsted County, Minnesota. Gastroenterology. 1997;112:1448-56.

19. Posner S, Zheng J, Wood RK, et al. Gastroesophageal reflux symptoms are not sufficient to guide esophageal function testing in lung transplant candidates. Dis Esophagus. 2018;31.

20. Fortunato GA, Machado MM, Andrade CF, Felicetti JC, Camargo Jde J, Cardoso PF. Prevalence of gastroesophageal reflux in lung transplant candidates with advanced lung disease. J Bras Pneumol. 2008;34:772-8.

21. Terra RM, de Medeiros IL, Minamoto H, Nasi A, Pego-Fernandes PM, Jatene FB. Idiopathic tracheal stenosis: successful outcome with antigastroesophageal reflux disease therapy. Ann Thorac Surg. 2008;85:1438-9.

22. Walner DL, Stern Y, Gerber ME, Rudolph C, Baldwin CY, Cotton RT. Gastroesophageal reflux in patients with subglottic stenosis. Arch Otolaryngol Head Neck Surg. 1998;124:551-5.

23. Blumin JH, Johnston N. Evidence of extraesophageal reflux in idiopathic subglottic stenosis. Laryngoscope. 2011;121:1266-73.

24. Jarmuz T, Roser S, Rivera H, Gal A, Roman J. Transforming growth factor-beta1, myofibroblasts, and tissue remodeling in the pathogenesis of tracheal injury: potential role of gastroesophageal reflux. Ann Otol Rhinol Laryngol. 2004;113: 488-97.

25. Bain WM, Harrington JW, Thomas LE, Schaefer SD. Head and neck manifestations of gastroesophageal reflux. Laryngoscope. 1983;93:175-9.

26. Little FB, Koufman JA, Kohut RI, Marshall RB. Effect of gastric acid on the pathogenesis of subglottic stenosis. Ann Otol Rhinol Laryngol. 1985;94:516-9.
27. Koufman JA. The otolaryngologic manifestations of gastroesophageal reflux disease (GERD): a clinical investigation of 225 patients using ambulatory 24-hour $\mathrm{pH}$ monitoring and an experimental investigation of the role of acid and pepsin in the development of laryngeal injury. Laryngoscope. 1991;101: $1-78$.

28. Toohill RJ, Ulualp SO, Shaker R. Evaluation of gastroesophageal reflux in patients with laryngotracheal stenosis. Ann Otol Rhinol Laryngol. 1998;107:1010-4.

29. Munir RA, Ehtisham M, Klopper E, Hammond K, Musani AI. Correlation between tracheal stenosis and gastroesophageal reflux disease. Am J Respir Crit Care Med. 2015;A3075.

30. Cheng T, Carpenter D, Cohen S, Witsell D, Frank-Ito DO. Investigating the effects of laryngotracheal stenosis on upper airway aerodynamics. Laryngoscope. 2018;128:E141-9.

31. Boesch RP, Shah P, Vaynblat M, Marcus M, Pagala M, Narwal S, et al. Relationship between upper airway obstruction and gastroesophageal reflux in a dog model. J Invest Surg. 2005;18:241-5.

32. Masuda T, Mittal SK, Kovacs B, Smith M, Walia R, Huang J, et al. Thoracoabdominal pressure gradient and gastroesophageal reflux: insights from lung transplant candidates. Dis Esophagus. 2018;31:619-29.

33. Costerton JW, Montanaro L, Arciola CR. Biofilm in implant infections: its production and regulation. Int J Artif Organs. 2005;28:1062-8.

34. Bibas BJ, Terra RM, Oliveira Junior AL, Tamagno MFL, Minamoto H, Cardoso PFG, et al. Predictors for postoperative complications after tracheal resection. Ann Thorac Surg. 2014;98:277-82.

35. Kreuter M, Raghu G. Gastro-oesophageal reflux and idiopathic pulmonary fibrosis: the heart burn in patients with IPF can no longer be silent. Eur Respir J. 2018;51:1800921.

Key Words: esophageal motility, esophageal pH study, fundoplication, gastroesophageal reflux, tracheal stenosis 